\title{
Global Subunit Specialization: An Organizational Perspective
}

\author{
Carlos Adrian Rodriguez \\ Ph.D awarded by McGill University, Canada (August 2014)
}

\section{Introduction}

The last 25 years have seen significant changes in the organization of firms' value chain. Fostered by technological innovation and institutional changes, companies are increasingly reconfiguring their global footprint to improve their access to specialization and location advantages. This phenomenon has significant implications to the research and practice of international business, as the fine-slicing of value chain activities is creating fundamental modifications to the way that firms compete (Lewin \& Peeters, 2006).

A large body of knowledge has been developed to understand offshoring/ outsourcing decisions and their firm- level implications (see Hätönen \& Eriksson, 2009; Schmeisser, 2013, for reviews); however, much less research has explored value chain disaggregation as an organizational process, in particular, the design choices involved as new subunits form and expand. My thesis seeks to contribute to this area by analyzing the formation and evolution of fine-slicing initiatives, as well as the role of architectural mechanisms in fostering the emergence of capabilities for the firm.

Fine-slicing refers to the disaggregation and dispersion of a firm's value chain into its constituent sub-activities and processes (Contractor, Kumar, Kundu, \& Pedersen, 2010). By increasing the level of modularity and globalization of their operations, firms can leverage the specialization and standardization of their activities, concentrate operations (in locations where comparative advantages to perform those activities exist) and adopt ownership structures according to their skills and focus areas (Buckley \& Ghauri, 2004). Despite these advantages, managing disaggregated and dispersed operations has proven difficult for organizations adopting fine-slicing (e.g., Aron \& Singh, 2005).

In order to understand the organizational challenges of fine-slicing operations, I focus on the development trajectory of the resulting "specialized" subunits. The first paper of the dissertation investigates how the selection of an initial activity and locational scope affects the subunit's performance. The second paper analyzes the effect of attaining performance expectations over the subunit's expansion trajectory. Finally, the third paper implements a qualitative exploration of how changes in the subunit's organizational architecture affect its capability development process. In addition, throughout the dissertation, I devote significant attention to the impact that ownership mode (either in-house or outsourced) has on the process.

The papers in my dissertation utilize data on the offshoring of administrative and technical services (A\&T) collected by the Offshoring Research Network

(ORN), which I combine with other information sources. Several reasons support the selection of A\&T ORN data for studying the development trajectories of fine-slicing units. First, fine-grained data at the firm, project and location levels provided the unmatched ability to perform quantitative analyses and a qualitative exploration on the initial establishment and development trajectories of the fine-slicing initiatives. Second, the period covered in the analysis (1995-2012) covers the most relevant stages of this activity, which allows for more reliable inferences of causality from the observed empirical associations.

\section{Summary of Studies}

My first study examines the impact of the subunit scope (functional and geographical breadth) over the project's efficiency. Fine-slicing projects can start by little "toe-in-the-water" approaches, or can follow a larger adoption scheme that incorporates multiple functions, areas of expertise and countries. Yet, no exploration in the literature exists as to how this choice affects the project's efficiency. I examine this issue by comparing the level of savings achieved by firms that have started offshoring either by locating an activity in multiple locations or by locating multiple activities in a single country, against the efficiency attained by firms that are starting by implementing single projects in single locations. I find four scope effects on subunit efficiency: (1) geographical scope effects, which reduce efficiency when dispersed activities are related; (2) functional scope effects, which increase efficiency the larger the number of functions is in a given location; (3) structural complexity effects, which decrease efficiency the larger and more intricate the subunit becomes; and (4) ownership mode effects, which moderate geographical and functional linkages in outsourced subunits.

This study makes three contributions to the international business literature. First, it is the first analysis that quantitatively tests the relation between a subunit's scope and its efficiency. Second, it separates the influences of different dimensions-geographic scope, functional scope, and structural complexity - thus providing a fine-grained exploration of the distinct mechanisms affecting activity efficiency in fine-slicing activities. Third, it suggests aggregated configurations, depending on the ownership structure of the fine-slicing unit: fully owned settings are likely to benefit more from an initial establishment within the boundaries of a country, while outsourced settings are better suited to exploit resource advantages in multiple locations.

My second study analyzes the role of experience in shaping a firm's value 
chain internationalization. Scholars have argued for experiential learning effects guiding offshoring (e.g., Maskell, Pedersen, Petersen, \& Dick-Nielsen, 2007); however, no models have yet been proposed to describe how experience affects the expansion trajectories of fine-slicing initiatives. To create such a model, I analyze patterns of across-country and within-country expansion of fine-slicing initiatives and find that expansion trajectories are linked to the attainment of a certain level of aspirations in the previously executed projects. In particular, while financial aspiration fulfillment is linked to the decision of expanding existing activities across countries, I find that it is the achievement of operational expectations that explains the aggregation of new activities in an existing country.

The results of this second study present a significant contribution to the literature on the internationalization of value chain activities. It presents a model that describes how experiential learning affects the definition of expansion trajectories and advances specific insights on performance rubrics influencing the process: financial performance rules guide geographical expansion in a given activity, and operational performance rules guide functional expansion within a given country.

My third study explores how changes in the organizational architecture of a fine-slicing project affect capability development. The existing literature describes the role of organizational traits in capability creation; however, a detailed account of how changes in a firm's architecture enable the development of capabilities has not yet been explored (Felin, Foss, Heimeriks, \& Madsen, 2012). Drawing on two in-depth case studies developed in the context of business service offshoring, this paper contributes to the literature on capability evolution in three ways. First, it theorizes that narrow scope roles and performance metrics are the fundamental channels used to guide capability emergence in the initial stage of offshoring in both in-house and outsourced centers. Second, it suggests that incipient capability emergence creates a push for increases in functional integration with other firms' units, regardless of whether the firm adopts in-house or outsourced offshoring methodologies. Third, it theorizes that advanced stages of offshoring show a larger dispersion of organizational architecture tools in in-house or outsourced offshoring settings; indeed, such tools are selected to tie the leveraging of already developed capabilities to support the firm at large.

\section{Implications for Theory and Managerial Practice}

Overall, this dissertation offers a new perspective on the process of disaggregation and dispersion of a firm's activities. By centering on the formation and evolution of the subunits resulting from fine-slicing processes, this dissertation contributes in four distinctive ways to the IB literature: (1) by illuminating the particular mechanisms affecting the relation between initial scope and efficiency; (2) by clarifying the role of experience and the learning rules guiding internationalization sequences on value chain activities; (3) by exploring the type of organizational design interventions that can contribute to the capability development process and; (4) by offering a detailed account of how the in-house/outsource decision affects other organizational choices.

The empirical goal of this dissertation is to guide managers to see fineslicing not as a one-time strategic decision, but rather one that is sensitive to architectural variables (e.g., functional scope, geographical scope, and attention mechanisms) and learning processes (about contracts, providers, locations, and architectural changes). This dissertation suggests an active role of managers not only in managing complexity (cf. Larsen, 2014), but also in developing proactive adjustments in the organizational structure to facilitate the capability development process, and progressively leverage those capabilities across the firm.

\section{References}

Aron, R., \& Singh, J. V. (2005). Getting offshoring right. Harvard Business Review, 83(12), 135-135.

Buckley, P. J., \& Ghauri, P. N. (2004). Globalisation, economic geography and the strategy of multinational enterprises. Journal of International Business Studies, 35(2), 81-98.

Contractor, F. J., Kumar, V., Kundu, S. K., \& Pedersen, T. (2010). Reconceptualizing the firm in a world of outsourcing and offshoring: The organizational and geographical relocation of high-value company functions. Journal of Management Studies, 47(8), 1417-1433.

Felin, T., Foss, N. J., Heimeriks, K. H., \& Madsen, T. L. (2012). Microfoundations of routines and capabilities: Individuals, processes, and structure. Journal of Management Studies, 49(8), 1351-1374.

Hätönen, J., \& Eriksson, T. (2009). 30+ years of research and practice of outsourcing - Exploring the past and anticipating the future. Journal of International Management, 15(2), 142-155.

Larsen, M. M. (2014). The organizational design of offshoring. AlB Insights, 14(3), 10-12.

Lewin, A. Y., \& Peeters, C. (2006). Offshoring work: Business hype or the onset of fundamental transformation? Long Range Planning, 39(3), 221-239.

Maskell, P., Pedersen, T., Petersen, B., \& Dick-Nielsen, J. (2007). Learning paths to offshore outsourcing: From cost reduction to knowledge seeking. Industry \& Innovation, 14(3), 239-257.

Schmeisser, B. (2013). A systematic review of literature on offshoring of value chain activities. Journal of International Management, 19(4), 390-406.

Carlos Adrian Rodriguez is an Assistant Professor at INCAE Business School. He obtained his Ph.D. in Strategy and Organizations at McGill University. His research centers on the processes of formation, evolution and organizational change triggered by the processes of fragmentation in the global value chain. Before entering into academia, he worked as a project manager at Procter and Gamble, where he was involved in the establishment of $P$ \& G's business services unit in his native Costa Rica. 